NOTAS $Y$ DISCUSIONES

\title{
Realismo ético y experiencia moral
}

\author{
ANTONIO VALDECANTOS \\ Universidad Carlos III de Madrid
}

El realismo ético es una vieja doctrina filosófica de difícil acomodo en la mente contemporánea. Se cree a menudo que, por una variada serie de circunstancias, los ciudadanos de las sociedades contemporáneas son espontáneamente antirrealistas y en gran parte esto es cierto. Entre los muchos argumentos para desacreditar el realismo ético, hay dos de no poco peso. Según el primero de ellos, la tesis realista no añade nada a la experiencia moral ordinaria y es perfectamente prescindible (con esto no se apoya el antirrealismo, pero sí se pone al realismo fuera de la discusión). De acuerdo con el segundo, el realismo quedaría refutado al ser incompatible con el pluralismo ético. Voy a tratar de sugerir que ninguno de estos argumentos es válido, lo que me exigirá esbozar - tan sólo esbozar de modo muy tosco y rudimentario, desde luego- una forma de realismo ético que pueda hacer frente a ambas objeciones.

\section{El realismo ético y la máxima de Peirce}

Se suelc llamar realismo ético a la doctrina según la cual los enunciados morales son verdaderos ofalsos y su verdad of falsedad es independiente de las opiniones y teorías morales que uno apruebe ${ }^{\prime} \mathrm{o}$, si se prefiere, a la idea de que hay hechos a verdades morales y esos hechos o verdades son inde- pendientes de la evidencia que pueda tenerse en favor de ellos ${ }^{2}$. No basta, pues, para ser realista con que se crea que las expresiones de norma o de valor aseveran cierto contenido cognitivo; es preciso sostener, además, que la verdad o falsedad de esas aseveraciones pertenecen a cierto tipo de cosas que se escapan del control de uno y de todos los que son como uno: al tipo de las cosas que se encuentran o se descubren y no al tipo de las que se construyen o inventan. Alguien puede creer, por ejemplo, que expresiones tales como «resulta un tanto sucio que alguien se deshaga de sus rivales amorosos sobornándolos» 0 «se le deberian subir los colores a Gervasio cada vez que piensa en publicar lo que le plagió a Nicasion son verdaderas (tanto, al menos, como lo son «la República Española ganó a los italianos la batalla de Guadalajara» o «Javier Marías no ha ganado el premio Nobel de 1997\%), y quizá trate de respaldar su creencia afirmando que ello es así porque las intuiciones mayoritarias 10 exigen, $o$ porque lo determinan las mejores teorías normativas disponibles, o porque eso es lo que decidiría cualquier individuo adulto después de discutir con cualesquiera otros en ciertas condiciones de imparcialidad e igualdad. Con esto tendríamos un caso de cognitivismo ético, pero un realista ba de creer algo más para distinguirse del mero cognitivista ${ }^{3}$. Los realistas éticos no sólo 
creen que las expresiones morales tienen que ser verdaderas ofalsas; se hallan también persuadidos de que no basta para acertar sobre ellas con tener una buena tcoría normativa o con poseer sentimientos morales equilibrados, con pertenecer a una tradición robusta o con algún otro recurso habitualmente solvente: de lo que se trata cuando se profieren enunciados morales es, sobre todo, de que uno tiene que acertar, y esto quiere decir que uno puede creer que acicrta (y aun crecrlo con las mejores razones disponibles) y $\sin$ embargo estar cquivocado. Acertar en ética no es, según el realismo, creer que se ha acertado, y ni siquiera lo es creer justificadamente que se cstá en lo cierto. Los realistas creen que en ética hay innumerables modos de equivocarse, que no conocemos todos esos modos (ni quizá podremos conocerlos nunca) y que sería absurdo presumir de estar inmunizado frente a ellos. No se trata, entonces, de que las verdades morales sean aquello que los mejores procedimientos disponibles permiten obtener; lo que ocurre según el realismo es que esos procedimientos son buenos precisamente porque con ellos se alcanzan enunciados verdaderos, y en la medida en que se alcanzan. Los realistas éticos creen que alguien puede estar en inmejorables condiciones para determinar lo que es bueno y para saber qué debe hacerse $y$, sin embargo, puede errar por entero; $y$, a la inversa, que alguien puede razonar de manera grosera y disparatada y no dejar de alcanzar, a pesar de ello, la verdadera noción de lo bueno y lo debido. Los realistas éticos aspiran, desde luego, al conocimiento verdadero justificado en cuestiones valorativas y normativas, pero admiten que puede haber en ellas conocimiento justificado no verdadero y también conocimiento verdadero no justificado ${ }^{4}$.

El realista ético es un individuo aficionado a conjeturar qué pasaría en caso de que las teorias normativas exitosas, o las convicciones morales mayoritarias o las emociones morales comunes ( $y$, desde luego, combinaciones de todo lo anterior) fueran por entero distintas de como son. Si nos imaginamos en posesión de una teoría normativa sorprendentemente brillante $y$ novedosa ( $y$ no hace falta que sepamos qué aspecto habría de tener ésta para calibrar algunas de las consecuencias que tendría el uso de una tcoría así), o convicciones mucho mejor formadas de las que tenemos, o emociones de más noble estofa aún desconocidas para nosotros, acaso nuestros juicios morales tendrían un aspecto muy distinto del que tienen, y por tanto variaría considerablemente la extensión de la clase de los enunciados tomados como verdaderos 5 . Todo lo anterior tiene un aspecto ferozmente especulativo, pero puede ilustrarse con ejemplos muy cotidianos. Acaso valga la pena acudir al caso de quien no posee competencia plena de una lengua o de alguien con un cociente intelectual muy inferior a la media. Un individuo que no domina adecuadamente el alemán hablado y que asiste a una reunión donde todos los demás sí lo dominan no sabe con precisión qué placer singular ocasiona el entender un chiste cuya gracia parece consistir en cierto juego de palabras muy rebuscado y que se le escapa, pero sí es capaz de imaginar qué pasaría si entendiera el chiste: disfrutaría de un rato agradable en la taberna cervecera en lugar de tener que disimular su ignorancia sin ningún éxito. Es cierto que el ignorante del alemán coloquial no sabe dónde está la gracia del chiste que acaba de oír, al igual que el disminuido mental lo ignora todo sobre las antinomias kantianas (salvo quizá el extraño nombre de «antinomias»), pero sí sabe en qué consiste entender adecuadamente un chiste, a semejanza del disminuido mental que es capaz de imaginar el tipo de vida que llevaría si estuviera en condiciones de entender cosas semejantes a las antinomias de Kant. Los realistas éticos creen que podemos estar, y que seguramente estamos a menudo, en la tesitura 
de quien sabe alemán de manera imperfecta y no entiende los chistes y de los deficientes mentales que no logran comprender un argumento metafísico. Los chistes son, entonces, buenos o malos ${ }^{6} y$ los argumentos metafísicos son válidos o especiosos aunque uno no lo sepa ni quizá llegue a saberlo nunca, y los enunciados morales son verdaderos 0 falsos aunque uno no esté en condiciones de poder asegurarlo. Contra lo que acaso podría parecer, la anterior intuición no obliga al realista a postular un reino de cosas en si en el ámbito moral; el realismo es una tesis sobre el lenguaje y el mundo, pero esto no significa que haya de afirmar algo sobre la naturaleza de ciertos hechos, sino sobre nuestra posibilidad de error al afirmar ciertos enunciados.

Que alguien sea realista ético o no pertenece en exclusiva, o eso es natural creer, a la metaética que profese, o sea, al conjunto de creencias que tenga sobre el lenguaje moral y la relación de él con el mundo. La respuesta que se dé a la cuestión del realismo y a las demás cuestiones metaéticas (o el abandono de estos quehaceres por nimios y tediosos) no habria de afectar, así pues, en nada al modo como se responda a las preguntas propiamente ćticas o morales de lo que se debe hacer $y$ de lo que es bueno o valioso. Entre quienes afirmen que se debe obrar de cierta manera particular o que hay que vivir de determinada forma habrá un buen número de realistas y también de antirrealistas (aunque predominatán quizá los que se desentiendan del problema o lo ignoren) y los desacuerdos metaéticos entre ellos no estorbarán en nada a la coincidencia que reine sobre los asuntos mismos ni tampoco podrá contribuir al acuerdo en caso de que no exista. De parecido modo, el ser realista o antirrealista no parece determinar en ningún sentido las tesis normativas o valorativas que se sostengan. Muchas gentes creen que la metaética es una ocupación plenamente ociosa, pero son todavia más quienes piensan que -ociosa o no- carcec de toda relación, o la tiene tan sólo anecdótica, con el contenido de la moralidad ${ }^{7}$. Uno aprueba, según ellos, las teorias normativas que le parecen mejores y sólo después, en caso de que por oficio académico tenga que entregarse a ocupaciones de este tipo, se pone a pensar quê significa el haber elegido una teoría más bien que ninguna o qué relación guarda lo que afirma esa teoría con otras cosas que uno cree sobre, por ejemplo, la existencia del mundo exterior o la naturaleza de los números, de las mentes ajenas o de los electrones. $\mathrm{Si}$ nadie emprende estas fastidiosas especulaciones, las teorías normativas no se resentirán de nada, porque la metaética es un puro entretenimiento de la filosofía académica más autista. En caso de que los aficionados a este modo de ver las cosas conozcan la llamada «máxima de Peirce», podrán asegurar en seguida que el problema del realismo ético «carece de efectos que puedan tener razonablemente repercusiones prácticas» ${ }^{8}$. Según ellos, lo que alguien crea, por ejemplo, sobre el multiculturalismo o sobre el suicidio es completamente independiente de sus creencias sobre el realismo. Alguien pucde, entonces, ser favorable a los derechos colectivos de las minorías étnicas y contrario al suicidio, o al revés, sin que importe nada que interprete sus creencias normativas de manera realista o antirrealista, o que tenga el menor interés en cómo hayan de interpretarse. Si ello es asi y si uno quiere dedicarse a problemas genuinamente normativos y de contenido, puede ocuparse de lleno en ellos y excusar sin remordimiento el trato con cuestiones metaéticas".

Yerran del todo los enemigos de la metaética al proclamar cuanto viene dicho. Trataré de mostrar de modo muy sumario en qué se equivocan, pero lo que más ha de importarnos ahora son las consecuencias que se seguirian del error en caso de que lo hubiera. Porque, si se prueba que 
las cuestiones metaéticas - y en particular la del realismo - andan vinculadas de manera estricta a las cuestiones propiamente éticas o morales y si se concluye que no toda metaética es compatible con cualquier concepción del bien o sistema normativo, sino que ciertos modos de juzgar lo bueno y lo debido llevan a tener que admitir ciertas doctrinas metaéticas y a negar otras, entonces cabrá argumentar a favor o en contra del realismo con algo más que meros argumentos sobre la naturaleza del lenguaje moral. Alguien podría mostrar, por ejemplo, que ciertos bienes sólo pueden considerarse tales si se adopta una concepción realista o que determinadas normas sólo serán válidas cuando se admita una metaética antirrealista, y ello convertiría al realismo o al antirrealismo en algo imprescindible para cualquiera que apreciase el bien en cuestión o que obedeciese razonadamente la correspondiente norma. Podría ocurrir, por ejemplo, que se nos convenciera con buenas razones de que el aprecio por la libertad sexual y el derecho a disponer del propio cuerpo sólo se sostienen coherentemente en caso de que se admita el realismo ético; si ello fuese asi y si además se determinase que resulta manifiestamente implausible un mundo donde la libertad sexual es despreciable $y$ donde la gente no tiene derecho a disponer de su propio cuerpo, entonces cabe creer que se habría obtenido un argumento de muy considerable peso en favor del realismo ético ${ }^{10}$.

La dicotomía entre metaética y ética normativa es, en realidad, la primera parte de una tricotomía: de la tricotomía entre metaética, ética normativa y moral. Una metaética, según se ha visto ya, es cierto conjunto de tesis sobre lo que significan las afirmaciones de que algo es una norma o una atribución de bien (o de mal); una ética normativa es cierto conjunto coherente y razonado y adecuadamente amplio de normas y de atribuciones de bien (o de mal) "1" una moral o moralidad es cierto conjunto de acciones y costumbres humanas (de un individuo, de un grupo o de todo el género humano, caso éste en el que ha de sustituirse «una moralidad» por «la moralidad") consideradas en cuanto a su capacidad para ser regidas por éticas normativas o para apartarse de ellas ${ }^{12}$. De este modo, el que la oración «el suicidio es reprobable» sea una expresión de emociones incapaz de verdad y falsedad pertenece a determinada doctrina metaética, que el suicidio sea reprobable es una atribución de mal perteneciente a ciertas éticas normativas y que algunos individuos estén dispuestos en virtud de motivos (más o menos fáciles de establecer) a evitar siempre el suicidio y rehuyan cometerlo corresponde a la moral o moralidad de esos individuos. Distinguir entre estas tres nociones tiene a menudo no poca utilidad, pero el distinguirlas no obliga a afitmar que sean independientes entre sí. Que hay una tricotomía de estas tres nociones no es algo que se siga de la definición de cada una de ellas; es tan sólo una tesis filosófica rebatible. Parece claro que una critica adecuada de la tricotomía de metaética, éti$\mathrm{ca}^{13}$ y moral exige muchas más páginas y energías de las que ahora podemos disfrutar. Pero acaso no sea necesario intentar aquí una demolición sistemática, en parte porque el esquema de ella ha sido sugerido ya en la discusion contemporánea ${ }^{14} \mathrm{y}$ en parte porque a lo que quiero mostrar puede bastarle con unas pocas observaciones muy generales ${ }^{15}$.

El dominio de lo que hemos venido llamando la «moral» está formado, según se ha dicho, por las acciones o costumbres humanas en cuanto aptas para la valoración o la referencia a normas. Pero el claborar lo que suele llamarse una «ética» no parece que sea nada distinto de una acción humana (y el dedicarse a la ética de manera habitual comparte, por cierto, con otras formas de actividad humana el constituir una costumbre más o menos institucionalizada) sujeta a valoración y a nor- 
mas que se pueden cumplir e infringir. Se habla sin violencia de buenas y malas éticas normativas, de los deberes que uno tiene que cumplir si las hace, e incluso de ćticas normativas excelentes y otras que no lo son tanto, y el hacer ética bien o mal es algo que anda bastante entretejido con otras acciones y costumbres parejamente aptas para la valoración y para cl sometimiento a normas (por ejemplo, con las normas de honestidad que uno ha de observar cuando publica escritos o cuando da clases o seminarios o cuando pertenece a instituciones doctas) ${ }^{16}$. Lo mismo vale, desde luego, de lo que se llama «metaética" (las hay buenas y malas; uno puede obrar bien o mal cuando se dedica a la metaética). La ética normativa y la metaética pertenecen, pues, a la moralidad; son dos de las muchísimas cosas que forman parte de la moral, y están muy estrechamente vinculadas a otros componentes de ella. Por su parte, muchas éticas normativas constituyen la presentación más o menos ordenada y pulida de lo que ciertos grupos humanos han admitido espontáneamente como bueno o correcto en su conducta real (la ética es una especie de moral mejorada o pasada a limpio), mientras que otras éticas mantienen con la moral un trato de no poca intimidad al esforzarse por corregirla y enmendarla de manera sañuda. Ni las éticas que ordenan y pulen ni las que corrigen y enmiendan serían reconocibles si se ignorase la moral de que partieron, porque fuera de ella carecerian de todo sentido. Hay innumerables formas de desempeñarse en medio de una moral; una de ellas es hacer éticas normativas que reordenan y otra intentar éticas normativas que tratan de emprender reformas ambiciosas y también, desde luego, enmendar y criticar esas teorias, lo cual puede verse como una contribución a la historia de ellas o a la prehistoria de sus sucesoras. Pero estas tareas no son, por fortuna, patrimonio exclusivo de los profesores de filosofía moral y disciplinas afi- nes; casi todas las éticas que han tenido cierto peso extraacadémico han sido el resultado de la aportación de gentes muy variadas y con ocupaciones diversas. Toda ética normativa vigorosa se halla en proceso constante de reelaboración y, si ese proceso se lleva a cabo en una sociedad democrática pluralista, raramente cobrarán mucho protagonismo cn él la filosofía y la teoría social académicas: la tarea se repartirá entre legiones de periodistas, literatos, dirigentes políticos, clérigos, artistas, héroes contraculturales, visionarios, profesionales de la salud y gentes sin adscripción gremial clara. Toda moral compleja $-y$ las contemporáneas se dice que lo sonlleva incorporada la huella de varias éticas normativas que un día dejaron sentir su presencia. La moral puede verse casi siempre como un conjunto de «restos de teorías» ${ }^{17}$ que se encaman en la práctica y que surgieron a partir de prácticas anteriores ${ }^{18}$.

Hablar de ala moral puesto a ver la conducta humana como una complicada maraña de acciones y de pautas de acción que no serían las que son sin éticas normativas anteriores -acaso desechadas u olvidadas- ni sin una o varias éticas normativas más o menos explícitas en proceso de elaboración (nadie observa la conducta humana sin supuestos normativos implícitos), y que no serían como son sin alguna idea implícita de lo que significa en último término el tener éticas normativas o creer en ellas. Lo que se ha llamado metaética es la consideración de lo que uno hace cuando hace teorías normativas o cuando les presta asentimiento $y$, en este sentido, la metaética es una parte de la moral. La metaética, la ética y la moral no son, pues, independientes. No toda doctrina metaética es compatible con cualquier teoría ética normativa, y no toda teoría ética normativa es apta para regir normativamente cualquier moral dada $(\mathrm{y}$, a fortiori, no toda doctrina metaetica es apta para cualquier 
moral). Si uno persevera en la creencia tradicional, tiene buenas razones para creer que la cuestión del realismo ético no ha de afectar en nada a las cuestiones normativas sustantivas. Pero, si se desconfía de dicha creencia, entonces cae por su propio peso que la metaética tiene que introducir alguna diferencia en la ética y en la moral. Tocaría a continuación tratar de determinar cuáles son esas diferencias.

\section{La estrictura holista de la experiencia moral}

«No puede haber verdad final alguna $-y$ no puede haberla ni en ética ni en física $\longrightarrow$, escribió una vez William James, «hasta que el último ser humano haya tenido su experiencia y dicho su palabra" ${ }^{19}$. James parecía estar convencido de dos cosas: de que sólo puede hablarse con rigor de la verdad en ética cuando se haya eliminado toda posibilidad de revisar esa verdad y de que, si se ha de decidir sobre la verdad de un enunciado ético particular, es obligado acudir a cierta escurridiza entidad de tipo holista llamada experiencia. La primera de estas dos ideas resulta, desde luego, mucho más clara que la segunda. La «experiencia» a que aquí se refiere James podría acaso ser ilustrada por un conocido paso de su ensayo «A World of Pure Experience»:

«Para ser radical, el empirismo no ha de admitir entre sus construcciones ningún elemento que no sea directamente experimentado, ni tampoco excluir de ellas ninguno que se experimente de manera directa. Según tal filosofía, las relaciones que conectan experiencias deben ser por su parte relaciones experimentadas, y cualquier tipo de relación experimentada ha de considerarse tan "real" como chalquier otra cosa del sistema. Sin duda alguna, los elementos se pueden tedistribuir al corregirse la localización original de las cosas, pero en la disposición filosófica final siempre se tendrá que hallat un lugar real para cada uno de los tipos de cosa experimentados, ya sean términos o relacioness ${ }^{20}$.
Es oscuro lo que James entiende por «disposición filosófica final» (final philosophical arrangement), pero lo visto hace un momento sugiere que la descripción definitiva, filosófica o de cualquier otro tipo, de la experiencia no puede ser nada distinto de lo que sería una descripción - humanamente imposible- de la última experiencia humana. Lo más característico de esta idea de experiencia es que tiene que concebirse como un proceso de continuas mudanzas, de kredistribuciones» constantes de elementos y de relaciones ${ }^{2 !}$. Esto invita a usar la palabra kexperiencia» para designar conjuntos organizados de elementos tales como creencias, deseos, intenciones, emociones y otras actitudes proposicionales ${ }^{22}$, objetos de esas actitudes, acciones llevadas a cabo en virtud de ellas, y relaciones entre los anteriores elementos. Esos conjuntos podrían definirse, según escalas múltiples, en relación con individuos, con comunidades y con la humanidad entera y estarían sujetos a dos condiciones: sólo podrían definirse de manera provisional y las definiciones producidas pasarian a formar parte de una nueva configuración de la experiencia, describible a su vez por medio de nuevas definiciones de conjuntos.

¿Es útil para algo csta complicada idea de «la experiencia»? Me parece que sí lo es para proporcionar el marco adecuado a la discusión sobre si el realismo metaético es ética y moralmente indispensable o no. Esa visión de la experiencia invita a examinar la moralidad de manera holista, como una trama inabarcable de elementos $-y$ de relaciones entre ellos- entretejidos de manera variable y como la historia, necesariamente inconclusa, de las sucesivas descripciones de esa trama. Debería mos ahora revisar un poco, aunque la revisión se limitará a un cambio de énfasis, lo que nos habiamos propuesto al concluir el anterior apartado. Lo que esperábamos era poder descubrir las diferencias que el realismo introduce en la ética y en la moral, 
y eso exigía determinar en la ética y en la moral algunos contenidos cuya vigencia no se daría si no se interpretasen en términos realistas. La apelación a la «experiencia" no nos hace abdicar de este propósito; nos sugiere, por el contrario, una manera de lograrlo. Lo que ahora podemos proponernos es examinar el aspecto que suelen ofrecer las descripciones de la experiencia, reducida por razones de economía expositiva a la experiencia individual. $\mathrm{El}$ objeto de mi pregunta es normativo (lo que me interesa principalmente no es saber cómo describen de hecho su experiencia los individuos, sino qué descripciones nos parecen dignas de elogio) y no obliga al descubrimiento de reglas o criterios (renuncio a poder enumerar exhaustivamente los rasgos que convicrten a algo en una buena descripción de la experiencia). Con este cambio de enfoque no he abandonado mi proyecto primitivo. El describir la propia experiencia es, desde luego, una acción humana con efectos prácticos muy numerosos - y a veces forma parte de una costumbre, práctica o institución- que cae dentro de la moralidad y que puede estar regida por éticas normativas diversas (puede estarlo, y sin duda lo estará de ordinario, por éticas de la autenticidad o de la veracidad que aconsejan cierta forma de autodescripciones y excluyen otras ${ }^{23}$ ). Se trataba de ver, recordemos, el modo como la cuestión del realismo afecta a este problema.

En la red de la experiencia hay, entre otros elementos, creencias y deseos. Es corriente sostener que las creencias y los deseos pueden ser de primer orden y de órdenes superiores. Si creo que mucha gente pasa hambre en Abisinia tengo una creencia de primer orden, pero si creo que esa creencia mía me obliga a tratar dc cooperar para eliminar o reducir el hambre de los abisinios, tengo una creencia de segundo orden, creo cosas en relación con otras cosas que creo. Si deseo adquirir una buena edición de los aforismos completos de Lichtenberg en alemán, ese deseo es de primer grado, pero si, dado que ya lo tengo, lo que deseo ahora es no tener la tentación de gastar el importe de la edición de Lichtenberg en una excursión de fin de semana a Sigüenza y Soria, entonces mi deseo es de segundo orden. Deseo cosas en relación con mis deseos: deseo desear unas más que otras. Normalmente, la idea de una jerarquía entre órdenes de creencias y de deseos se emplea para dar cuenta de episodios o situaciones de conflicto. Alguien cree que existe un dios todopoderoso e infinitamente bueno y cree también que ciertas catástrofes naturales son abominables y no podrían tener nunca justificación. La segunda creencia puede enunciarse diciendo que la primera está sujeta a dificultades muy severas, y ello obliga a buscar un arreglo a ese desacuerdo entre creencias. Alguien desea ardientemente fumar a menudo en cachimba tabaco de la marca "Balkan Sobranic» y desca también llegar a viejo para concluir un estudio muy exhaustivo sobre la debilidad de la voluntad en la cultura occidental. Este segundo deseo, y la creencia de que puede contraer úlcera de estómago y cáncer de pulmón, de lengua y de labios, to lleva a desear no fumar «Balkan Sobranie» ni ninguna otra cosa, de modo que tiene un deseo de segundo orden opuesto a su deseo de primer orden y seguramente se esforzará por arreglar como pueda el conflicto. Todo esto es conocido y objeto de creciente atención por disciplinas muy variadas, no sólo ni principalmente filosóficas ${ }^{24}$.

En general, nadie puede tener creencias ni deseos mínimamente sólidos si no dispone de un abigarrado repertorio de otras actitudes proposicionales: de emociones ${ }^{25}$. Nadie puede, por ejemplo, creer nada muy consistente sobre lobos si no cree que los lobos son de temer, pero para creer esto uno tiene que haber experimentado temor alguna vez, aunque no necesariamente temor de un lobo; el inepto emotivo es 
un inepto epistémico. En particular, nadie puede tener creencias sobre acciones si no tiene ciertos tipos de emociones. Nadie puede creer nada de mucha enjundia sobre dádivas si ignora que las dádivas son de agradecer, pero para ello no puede ser insensible a la gratitud; el inepto emotivo es también un inepto moral. Los racimos de creencias sobre acciones están muy bien anudados a los racimos de emociones sobre acciones. Pero las emociones poseen un rasgo interesante: ellas son o favorables $o$ desfavorables ${ }^{26}$. Las emociones llevan, podría decirse, un sí o un no en su interior y muchas veces lo favorable o desfavorable de ellas se transporta a las creencias ${ }^{27}$. Lo que vale de la relación entre creencias y emociones vale también del vínculo entre emociones y deseos. Para que las creencias y los deseos de uno estén en orden, han de estar en orden también sus emociones. Ciertas acciones humanas producen por lo general emociones favorables (como la admiración, el contento, el orgullo o el júbilo), y otras las suelen producir negativas (como la ira, la vergüenza, la indignación o el asco). Si mis capacidades emotivas estuviesen cercenadas y me faltase toda aptitud para el enojo o la ira, mi competencia para entender algunas acciones, como las consistentes en una venganza - y digo para entenderlas, no para valorarlas, que esto parece ir de suyo- estaría severamente disminuida, y también lo estaría mi capacidad para desear emprender ciertos cursos de acción. Las creencias, los deseos y las emociones andan entretejidas de un modo muy fuerte. Uno no tendría ciertas emociones si no creyera ciertas cosas y no deseara otras y no creería algunas cosas de no haber tenido determinadas emociones y experimentado ciertos deseos. Pero, en un sentido más elemental, uno cree cosas sobre emociones (por ejemplo, que la ira puede moderarse) y experimenta emociones sobre creencias. Todas las emociones están con respecto a las creencias en una suerte de relación de segundo grado (pues nadie experimenta cierta emoción si no cree algo que interviene en la formación de ella) y a veces también ocurre a la inversa. Esto invita a pensar también en emociones que toman a otras emociones como su objeto, en emociones de segundo orden en un sentido claro: podemos enorgullecernos de nuestra indignación o temer nuestra propia ira ${ }^{28}$. No cabe imaginar un individuo humano sin la capacidad de tener emociones de segundo grado, salvo que se disfrute imaginando compañeros de especie un poco monstruosos. El entretejimiento, pues, de creencias y emociones (como el de emociones y descos) lo es de dos familias de cosas que, a su vez, pueden ser de primer y de segundo orden, y seguramente también de órdenes superiores.

La experiencia es una red que se va tejiendo y desgarrando continuamentc (o que va «redistribuyendo sus elementos y relaciones», como diría James) y en ese proceso de redistribución desempeña un papel muy destacado la formación de creencias, deseos y emociones de segundo orden. Esto convida a pensar que los individuos no están atrapados en la red de su experiencia, sino que tienen cierta capacidad de cambiarla a sabiendas. Ser capaz de creencias, deseos y emociones de segundo grado significa ser capaz de elegir hasta cierto punto creencias, deseos y emociones. La vida mental de los individuos humanos está urdida de tal modo que hay creencias, deseos y emociones que ellos pucden elegir, pero esto significa, naturalmente, que hay creencias, deseos y emociones que no. La idea de un individuo humano absolutamente rígido incapaz de modelar siquiera en una minima parte su repertorio de creencias, deseos y emociones es una idea monstruosa ${ }^{29}$, pero la idea de un yo completamente plástico es quimérica. Si alguien describe su propia experiencia moral afirmando que no cree que pueda formar creencias, emociones $y$ deseos de segundo orden y que además 
no quiere hacerlo incurre en una afïrmación que se refuta a sí misma (pues al enunciarla así ha ascendido al segundo nivel de sus creencias y deseos) y se provoca quizá a sí propio una emoción muy negativa de autodesprecio ${ }^{30}$. Estas descripciones de la experiencia propia aúnan dos rasgos que las invalidan: son falsas y, en caso de que fueran ciertas, serían repudiables. Algo semejante sucedería con quien se describiera a sí mismo como un individuo que no encuentra trabas a su continua autotransformación. La capacidad de reinventarse constantemente no pertenece a las capacidades humanas, y nadie puede atribuírsela con verdad a sí mismo. Es también una afirmación que se autoanula - si digo que soy alguicn en continua reinvención tendré que afirmar que mi yo de dentro de dos días no será alguien en continua reinvención- y algunas de cuyas consecucncias (como la renuncia a toda responsabilidad por las acciones propias) desencadenan inevitablemente emociones de desprecio ${ }^{31}$. Estamos, pues, compelidos a vernos como seres que necesitan de cierta mudanza de creencias, de deseos y de emociones, pero que no pueden excederse en su autotransformaciôn. Lo que vale para el abandono de estas actitudes proposicionales y para la adquisición de otras nuevas vale también para la formación de creencias, deseos y emociones de segundo orden y de órdenes superiores. Nadie puede quedarse siempre en el piso bajo, pero tampoco hay nadie que pueda permanecer todo el tiempo en movimiento ascendente. No podemos vernos como definitivamente rígidos ni como indefinidamente plásticos, y no podemos, cabe pensar, porque no somos ni una cosa ni la otra. Las ideas de un yo rígido y de un yo plástico son repudiables para cualquier ética normativa coherente e inviables en cualquier moralidad que quepa imaginar. Son también inconsistentes, $\mathrm{c}$ incompatibles con $\mathrm{cl}$ conocimiento que poseemos de la condición humana. Alguien que describa su experiencia conforme a ellas la describe mal, tanto en sentido normativo como fáctico. Rompe un nudo crucial de la red de su experiencia y hace que se aflojen peligrosamente otros nudos de ella. No es una licencia retórica afirmar que se comete un error ni que se trata de un error ético $y$ moral. Pero el descubrimiento de errores eticos y morales ha de formar parte de algo a lo que puede llamarse conocimiento ético y moral y que puede ser verdadero o falso. Creo que lo anterior es un argumento en favor de que ciertos contenidos normativos nada triviales ni anecdóticos exigen una determinada metaética y excluyen otras. La metaética a que obligan es, según lo hasta ahora visto, una forma de cognitivismo. Falta por ver si además es realista.

Los seres humanos adultos e inteligentes (y, podria añadirse, sociales, aunque el anadido es redundante) que describen adecuadamente su experiencia y rehuyen el error en sus descripciones se fundan en dos «intuiciones preteóricas» ${ }^{32}$. La primera es que el conjunto de sus creencias está normalmente en orden, en la medida en que puede estarlo. Las creencias $-\mathrm{y}$ también otras actitudes proposicionales- de uno están coherentemente organizadas y es imposible que sean erróneas en masa ${ }^{33}$. Podemos llamar a lo anterior la intuición fiabilista. Pero que el conjunto de mis creencias esté en orden no quiere decir que yo pueda estar seguro de que debo mantener contra viento y marea uha creencia dada cualquiera (al fin y al cabo, ella podría ser de las pocas que están de más en mi red de creencias). Es posible que esté del todo equivocado en esta creencia concreta y que tenga que abandonarla a ella y a otras de mi red. Llamarcmos a esta idea la intuición falibilista. Seguramente, nadie puede desempeñarse en la vida (en una vida mínimamente rica, en la que uno habla a menudo de la experiencia propia y ajena y los demás le escuchan a veces, pero no conozco otras lormas de vida ni 
a nadic que las conozca) sin alguna versión de las intuiciones fiabilista y falibilista. Quien sólo posee la primera de estas dos intuiciones sin atemperarla con la segunda cs un monstruo «rígido» dificil de concebir y quien sólo tiene la segunda es un correlativo monstruo eplástico». Estas dos intuiciones podrían expresarse en forma de imperativo hipotético problemático o «regla de la habilidad" a la manera de Kant: «si quieres desempeñarte adecuadamente en la vida, ten la intuición fiabilista y también la falibilista», y también sin duda, y con ventaja, como el correspondiente imperativo hipotético asertórico o «consejo de la prudencia»: «comoquiera que tienes que querer desempeñarte adecua damente en la vida, ten la intuición fiabilista y también la falibilista». Una y otra intuición son, entonces, indispensables en la vida moral y en la elaboración de cualquier ética normativa coherente, por las mismas razones que hace un momento se apuntaron contra las ideas de un yo rígido y un yo plástico. Pero las intuiciones fiabilista y falibilista juntas ticnen que dar lugar a cierto tipo de metaética realista y no meramente cognitivista. Si alguien quiere ser fiel a ellas, no le basta con afirmar que ciertos enunciados normativos de crucial importancia tienen que ser verdaderos o falsos; ha de afirmar también que su verdad o falsedad puede escapar, y de hecho escapa a veces, a los procedimientos normales para determinarla. Es condición constitutiva de las deseripciones de la experiencia moral humana el poder ser mejoradas o modificadas echando mano de recursos de los que no se dispone al elaborar la descripción o mejorando de manera insospechada y novedosa el aprovechamiento de esos recursos. Si los enunciados normativos han de poder ser verdaderos $-y$ algunos de ellos, muy cruciales, to son-, esto se debe a que a veces se logra disipar errores morales que son al mismo tiempo fácticos. Pcro no se sabe que algo es un error hasta que no se ha descubierto, y nada autoriza a creer que los procedimientos ordinarios para llegar a enunciados aceptables nos inmunizan contra el error. Tan sólo nos inmunizan contra el error masivo, pero a veces el error local puede ser funesto. Creernos inmunes al error normativo local significaría creernos demasiado cercanos a la kverdad final que James identificaba con la aniquilación de toda experiencia. No acertamos porque nuestros modos de razonamiento sean buenos; nuestros modos de razonamiento se hacen buenos (tan sólo provisionalmente buenos) cuando nos permiten desenmascarar como errores enunciados que dábamos por verdaderos. No fabricamos ni construimos la verdad; tropezamos con ella cuando fracasamos en las vías habituales de obtenerla.

\section{Realismo ético de segundo grado}

Del realismo ético parece seguirse una conclusión muy fuerte acerca de la naturaleza de los enunciados morales: para cada pregunta bien expresada que se suscite en el ámbito de la moralidad tendría que haber una y una sola respuesta correc$\mathrm{ta}^{34}$. La conclusión es ciertamente fuerte, pero resulta natural si se acepta la interpretación realista: es fácil encenagarse a menudo en preguntas morales difíciles que no sabemos cómo responder, pero esto puede deberse a que nuestros modos de responder a esas preguntas están poco desarrollados a son defectuosos; bajo esquemas mejores, de los que aún no disponemos, muchas preguntas descorazonadoras podrán obtener una respuesta satisfactoria y una sola. Lo que deberían proclamar quiencs creen en la existencia de conflictos morales «trágicos» imposibles de resolver es simplemente que todos los medios conocidos de resolverlos han fracasado hasta ahora, pero nadie estaría autorizado a concluir que éste es un cstado de cosas irrebasable o definitivo. No sólo 
no debe descartarse una mudanza a mejor en nuestro estado de perplejidad, sino que hay que confiar en yue se produzca. La intuición falibilista y la fiabilista parecen salir en ayuda de esta visión de las preguntas difíciles: el racimo de las creencias morales de uno tiene que ser mayoritariamente verdadero, aunque ninguna de ellas en particular esté inmune al error, y esto sugiere que hay una única respuesta correcta -y no dos o más incompatibles entre sí, o ninguna- a cada una de ellas, ya sea que la respuesta esté en nuestras manos, ya sea que no lo esté, o incluso que no pueda estarlo. Puedo, en suma, fiarme de la mayor parte de las respuestas que doy a las preguntas morales, aunque quizá esté equivocado sobre si esta respuesta singular es la buena. En caso de que lo anterior sea correcto, debe concluirse que el realismo ético se halla estrechamente comprometido con una concepción unitaria y escalar, monista, del bien ${ }^{35}$. La totalidad de los bienes humanos se hallaría organizada en una única escala métrica dentro de la cual a cada uno de esos bienes tiene que corresponderle una y una sola medida, sin que quepa que dos o más bienes estén situados en un mismo punto de la escala. La manera de decidir entre dos o más bienes incompatibles entre sí y que compiten por ganar nuestra preferencia es averiguar cuál de ellos está situado en un punto más alto de la escala. Parece natural atribuir al realismo la tesis de que esa escala existe a pesar de nuestros fracasos en manejarnos bien con ella.

Pero esta exigencia del realismo ético es seguramente inaceptable. Los conflictos morales «trágicos» o radicales constituyen, creo, un episodio inevitable de toda moral y de toda ética normativa y ello desacredita sin remedio la concepción unitaria y escalar del bien ${ }^{36}$. Cualquier fenomenologia minimamente rica de los bienes humanos acaba en la conclusión de que hay escalas inconmensurables e incompatibles de bienes y de que la elección entre estas escalas es asunto de una decisión no racional. El alumno de Sartre que se debate entre alistarse en las Fuerzas Francesas Libres y cuidar de su madre abandonada ${ }^{37}$ o el Agamenón de Esquilo que ha de sacrificar a Ifigenia si no quiere echar a perder una expedición guerrera ${ }^{38}$ son dos ejemplos muy conocidos de conflictos sin solución racional entre escalas tivales. Uno puede creer, a pesar de todo, que este tipo de conflictos son aptos para una solución futura, pero esta creencia pone al realismo ćti$c o$ en una tesitura muy desafortunada. Voy a tratar de sugerir, sin embargo, que el realismo no sólo no necesita comprometerse con la implausible tesis de la unidad del bien sino que, adecuadamente entendido, puede favorecer una concepción pluralista de bienes múltiples $\mathrm{e}$ inconmensurables.

$\mathrm{Si}$ algunos conflictos de bienes son genuinamente radicales y si resulta del todo implausible concebir un mundo del que esos conflictos hayan sido desterrados, entonces no todas las preguntas del ámbito de la moralidad poseen una y una sola respuesta; abundarán, por el contrario, las que tengan dos a más mutuamente incompatibles $o$, lo que es 10 mismo, ninguna terminante ni definitiva. Para poder salir airoso de este trance, el realismo ético habria de revisarse severamente y convertirse en una doctrina mucho más modesta: la de que, dentro de cada escala, sí que hay una sola respuesta correcta a toda cuestión que en esa escala se pueda suscitar. El realismo ético naufraga cuando tropieza con el dilema de Sartre o con el de Esquilo, pero acaso era excesivo pedirle que resistiera tan procelosas adversidades y uno tiene que contentarse con destinarlo a travesías más bonancibles. Porque el alumno de Sartre sí sabe -o eso debe creerse si el dilema ha de tener sentidoque hay. una única respuesta correcta para el problema de cómo atender a sus obligaciones familiares y también para el de cómo ser coherente con sus convicciones 
políticas, lo mismo que Agamenón conoce cuál es la única manera de cumplir correctamente sus obligaciones como padre y también la única de obedecer a las exigencias de su oficio de rey. El conflicto no surge porque Agamenón o el alumno de Sartre hayan sido incapaces de dar con esas respuestas, sino precisamente porque lo han logrado sin asomo de vacilación en cada una de Ias dos escalas. Una doctrina tan adelgazada como lo es ésta resulta modestísima en comparación con las ambiciones del realismo ético hasta aquí visto, pero nadie ha probado que todo lo modesto sea insignificante o trivial. Si hubiera una sola escala ética -- es lícito concluir-, entonces el realismo ético sería la mejor doctrina disponible para dar cuenta de la totalidad de la experiencia moral. Muchos antirrealistas podrían estar dispuestos a admitir de buen grado la verdad de este condicional contrafáctico, aunque no es seguro que quieran dar un paso más y afirmar que all donde es pertinente usar de una sola escala ética está vigente el realismo ético. Si los únicos argumentos contra el realismo ético son los proporcionados por la existencia de escalas inconmensurables de bienes, entonces me parece que no quedaría más remedio que dar por bueno este modesto realismo parcial. Pero si, a pesar de todo, no se admite - y es bastante verosímil que haya quien no lo admita-, clo se deberá seguramente a que el antirrealista supone que la existencia de conflictos entre escalas rivales infecta de inconmensurabilidad a todo el razonamiento moral. Incluso allí donde no vemos ahora el conflicto moral radical es posible verlo mäs tarde o más temprano, porque el mundo moral es conflictivo de principio a fin. La suspicacia del antirrealista pertenece al estilo escéptico de pensar y cuenta con una vieja tradición en su pro ${ }^{39}$, pero también cuenta, por ello mismo, con un modelo de crítica muy sólido y persuasivo: la idea pragmatista y wittgensteiniana de que la duda exige justi- ficación ${ }^{40}$ y de que es al escéptico a quien toca mostrar por qué debe dudarse de cosas que nadie pone sensatamente en tela de juicio.

Que todo esto sea así constituye un argumento contra el realismo ético, pero no desde luego una defensa del antirrealismo ético generalizado (hay conflictos radicales, pero no siempre que uno delibera quế hacer está en un conflicto radical; hay escalas alternativas, pero no siempre hay que elegir entre ellas porque no nos afectan todas o porque nos basta con una). Tan sólo es una defensa de cierto antirrealismo ético parcial, pero esto equivale de manera tan diáfana como de ordinario inadvertida a abogar por un realismo ético parcial. Lo que vendrían a decir estos objetores del realismo ético es que de entre las preguntas morales ha de distinguirse cntre las que poseen respuesta única y las que no, y que para estas últimas ha de valer la metaética antirrealista. Un antirrealistá que crea esto tendrá muy poco que argüir, en caso de que quicra hacerlo, contra la consideración realista de las cuestiones morales que no susciten conflictos ni se refieran a escalas inconmensurables; sus argumentos no valen nada contra la idea de que hay una sola respuesta correcta para cantidades muy copiosas de preguntas morales. Muchos antirrealistas serán proclives, desde luego, a creer que un realismo ético así de parcial no merece llamarse realismo, pero lo que ahora ha de interesarnos no es eso. Lo que importa de la objeción antirrealista es que exige que el ámbito de las cuestiones morales se divida en dos: las que se ha mostrado que no admiten una y una sola respuesta correcta y las demás. Así expuesta, la objeciơn antirrealista es del todo atinada y la daremos por vâlida de ahora en adelante ${ }^{41}$.

Hemos admitido, pues, la tesis de que algunas preguntas moralmente pertinentes no admiten una y una sola respuesta correcta y su corolario de que hay dos tipos de preguntạs moralmente pertinentes, las 
que poseen una y una sola respuesta correcta y las que no. Séanos dado llamar a la primera la tesis de la pluralidad de los mundos ( $\mathrm{O}$ TPM; es una denominación más bien pomposa, desde luego, pero el inquietante aspecto de la tesis invita a un tono grave) y a lo que demanda el segundo la división del trabajo moral o orm. Creo que TPM y DTM no son obstáculos para el realismo ético; son razones para abandonar el realismo ético tal como lo hemos entendido hasta aquí y para pensar en otra cosa, a la que cabe llamar realismo ético de segundo grado. Quien niega que todas las preguntas moralmente pertinentes admiten una y una sola respuesta sostiene, desde luego, una tesis tocante a la naturaleza de los enunciados morales y su relación con el Inundo y contraria, por tanto, a otras tesis metaéticas. Pero lo dicho antes sobre la insolvencia de la tricotomía entre metaética, ética normativa y moralidad convida a pensar que expresiones muy semejantes a TPM pueden tomarse a veces como juicios normativos. Uno puede decir, inspirándose en TPM: «desiste de buscarles la respuesta correcta a preguntas que no la tienen", y también «sigue buscando la respuesta correcta aun a sabiendas de que no la hays, que son enunciados normativos de sentido opuesto y desaconsejan creer que TPM pueda parafrasearse como una norma coherente. Pero acaso alguien opte por otras paráfrasis: «hagas lo que hagas con ciertas preguntas, has de saber que no hallarás la respuesta» o sacostúmbrate a quitar de tu horizonte la esperanza de una respuesta correcta para todo», o incluso «obra de tal modo que no presupongas la existencia de una respuesta única allí donde no puede haberla». Estas tres últimas expresiones normativas se siguen, creo, de TPM unida a una premisa normativa adicional por el estilo de «evita el autoengaño sobre lo que sabes» ${ }^{42}$. Quien afirma que hay preguntas morales sin respuesta o con más de una y entiende su afirmación meramente como una tesis metaética sin consecuencias prác- ticas es alguien con una visión distorsionada o muy incompleta de sus creencias. No cabe creer en serio la tesis de la pluralidad de los mundos sin estar dispuesto a orientar la propia vida con arreglo a ella, aunque sólo sea en el sentido de sacar las consecuencias de la implausibilidad de la tesis contraria. Si alguien entiende sin distorsión TPM, cabe esperar que muchos trozos de su vida moral dependerán estrechamente de la tesis y también a la inversa. El enunciarla y el dar razones en pro suyo (o en contra de su negación) serán episodios normalmente entretejidos con actividades muy variadas, tanto públicas como privadas, de quien sostiene la tesis y constituirán partes muy importantes de su razonamiento práctico. Cabe aventurar que la creencia en la verdad de TPM es una creencia que los individuos adquieren después de un largo proceso de aprendizaje y reflexión. Seguramente, nadie cree en la pluralidad de mundos morales sin haber experimentado antes -quizá dolorosamente- la imposibilidad de conciliar escalas rivales de bienes; la negación de TPM tenderá a verse no sólo como un error cognitivo sino como la manifestación de la inmadure $z$ moral propia, o acaso de una inocencia perdida e irrecuperable. Quien cree conscientemente en la tesis de la pluralidad de los mundos $-\mathrm{y}$ creer TPM es haber llegado a creerla-, no puede imaginarse ya sosteniendo en serio lo contrario. Es probable que caiga a menudo en la tentación de suponer que TPM es falsa, pero esa tentación pertenece a la clase de las ensonaciones suicidas. Ceder a la idea de que hay una única escala de bienes tras haber ordenado la vida propia según la convicción contraria es como actuar creyendo que uno es inmortal o que puede llevar a cabo sucesivamente muchos planes biográficos incompatibles. Aunque uno se obstine en engañarse tenazmente sobre ello, los fracasos que irâ cosechando lo arrastrarán muy pronto a vencer el autoengaño, porque cualquier forma de vida 
social minimamente rica excluye que los individuos actúen funđándose en ese tipo de ensoñaciones. Seguramente, el momento en que uno se convenció de la verdad de тPм fue un episodio significativo de su biografía $y$, si imagina que de pronto la tesis se prueba falsa, ha de imaginar al mismo tiempo mudanzas muy grandes en su modo de concebir las cosas y de obrar. La tesis cumple admirablemente la máxima de Peirce. Importa notar para los propósitos de nuestra discusión que quien afirma la tesis de la pluralidad de los mundos proclama lo que a su juicio es una verdad. La TPM cxpresa una aserción perteneciente a lo que debe llamarse conocimiento moral: puede ser verdadera o falsa. Si admitimos la intuición falibilista, hemos de imaginarnos dispuestos a revisar la creencia en la verdad de TPM, pero, por el momento, creemos en ella y esto significa que creemos que sería un error creer en la tesis contraria. Si alguien cree que un conflicto moral radical no lo es está equivocado, y también lo está si piensa que entre dos escalas éticas inconmensurables puede eliminarse una.

Cabría creer que el sostener tPM es el producto de una manera particular entre otras de ver las cosas; determina una escala de bienes (el pluralismo es bueno en su ámbito) que ordena escalarmente las acciones según su mayor o menor grado de satisfacción del ideal pluralista. Pero, desde luego, hay otras escalas de bienes, las establecidas a partir de juicios según los cuales todos los bienes tienen que medirse con arreglo a un solo patrón. Alguien pluralista vive en un mundo donde tambien hay monistas y debe ascender a un pluralismo de segundo grado que reconozca la inconmensurabilidad del pluralismo de primer grado con respecto a otras visiones. El pluralista de primer grado puede, entonces, convertirse en un pluralista recursivo que aplica el pluralismo a su propia concepción metaética ${ }^{43}$. Resultará entonces un pluralismo de segundo grado que toma al de primer grado como una más de las escalas éticas inconmensurables que poseen vigencia. Según esta nueva tesis, habrá ocasiones de conflicto entre escalas pluralistas y escalas monistas y uno tendrá que ser pluralista a la hora de reconocer el fuero que cada una de ellas posee (lo que, generalizado, autoriza a ir formando un pluralismo de tercer grado y otros tantos de grados sucesivamente mayores). Pero el pluralista de segundo grado está en una tesitura tremendamente incómoda. Tiene que admitir que el pluralismo de primer grado establece una escala de bienes cntre otras, y esto significa, naturalmente, que ha de admitir que la negación del pluralismo tiene su propio ámbito de validez y que se darán seguramente situaciones en las que no quepa decidir entre el pluralismo y el monismo. Todo esto ticne el aspecto de un rompecabezas hecho con materiales que tienen que ver muy poco con la experiencia moral ordinaria y con cualquier situación humana imaginable. Pero no es así, porque cabe la posibilidad, hace un rato mencionada, de que alguien convencido de la TPM tenga la tentación de pasar a adoptar su contraria. Quien se encuentre en esta tesitura puede llegar a cierto arreglo entre su creencia y su tentación decidiendo que cada una tiene cierto dominio de validez y resignándose a que algunos casos de conflicto sean radicalmente indecidibles. Quizá cupiera tambiên imaginar casos de pluralismo de tercer grado y de grados superiores.

Lo enunciado por la TPM ha de tomarse como verdad, aunque uno esté abierto a reconocer que puede no serlo. Para ser pluralista hay que admitir que el pluralismo es un bien y que, por tanto, el monismo es un mal, y esto está muy cerca de decir que el pluralismo es verdadero y el monismo falso. Si soy pluralista, lo soy porque creo que hay distintas maneras de ver el mundo que son valiosas, pero no puedo ser un pluralista de segundo grado que admita también en cierto modo la incon- 
veniencia de ser pluralista. Puedo afirmar que hay, por ejemplo, cierta cantidad de modos de vida distintos $c$ incompatibles pero todos ellos valiosos, y entonces soy pluralista de primer grado. Esto me compromete a sostener que es verdad que esos modos de vida son valiosos y que es falso que sólo haya uno que lo sea. Si para poder ser pluralista de primer grado tengo que afirmar que el monismo es falso, entonces no puedo ser pluralista de segundo grado. Pero podemos ahorramos todo este trabajo, porque el pluralista de primer grado no está obligado a serlo de segundo grado ni de grados superiores ni puede, en rigor, serlo $^{44}$. Una intuición muy vieja sobre la verdad, que expresó a su manera Friedrich Schlegel, proclama que «cuanto más alejado se está de la verdad pura, más puntos de vista parciales existen sobre ella" ${ }^{45}$. Pero Schlegel no llevaba razón: al contrario, lo que demanda la verdad a veces son precisamente puntos de vista parciales y una cuidadosa división del trabajo moral. Hay preguntas morales que no admiten una sola respuesta correcta, pero si hay (o eso cabe creer a falta de mejor evidencia) una sola respuesta correcta a la pregunta de si hay preguntas sin una sola respuesta correcta.

\section{NOTAS}

' $R$. Boyd, whow to Be a Moral Realists, en $\mathrm{G}$. Sayre-MeCord (ed.), Esrays on Mord Realism, ftaca (Nueva York)/Londres: Comell University Press, 1988, pp. 181-82. Boyd ajade la exigencia de que alos cánones ordinarios de razonamiento moral -junto con los cánones ordinarios del razonamiento cientifico y del razonamiento fáctico ordinario-constituyen, al menos en la mayor parte de las circunstancias, un método de flar para la obtención y la mejora del canocimiento moral (aproximado).

${ }^{2}$ D. Brink, Moral Realism and the Foundations of Einics, Cambridge: Cambridge University Press, 1989 , Pp. 17 y ss, cit. por F.I. Davis, «Discourse Ethics and Fthical Realism: A Realist Realignment of Discourse Ethics», European Joumal of Philosophy, 2, 2 (1994), p. 132.

* Véase la taxonomía de los problemas del realismo que ha dado Peter Railton en «Moral Realism: Prospects and Problems», W. Sinnott-Armstrong, M. Timmons (eds), Moral Knowledge? New Readings in Moral Epistemology, Nueva York/Oxford: Oxford University Press, 1996, pp. 49-81.

4 E. Gettier, «Is Justified True Belief Knowledge?», Anowsis, 23 (1963), pe. 121-123. Fl artículo y textos sohre el problema de Gettier st encontrarán en P. K. Moser (ed.), Empirical Knowledge. Readings in Contemporary Epistemology, Lanham (Maryland)/ Londres: Rowman \& Littlefield, 1996, pp. 237-265.

- La mejor manera que conozco de expresar esto se dehe a Thomas Nagel, y creo que merece la pena citarla por extenso: aCualquier concepción del mundo debe incluir algún reconocimiento de su propia incompletitud: cuando menos admitirá la existencia de cosas o sucesos de los que ahora no tenemos conocimiento. La cuestión es sólo cuánto debemos admitir que pueda extenderse el mundo más allá de nuestra concepción efectiva del mundo. Yo afirno que éste puede contener no sólo lo que no conocemos y sin embargo no podemos concebir; $y$ afrrmo tambiér que este reconocimiento de la probabilidad de sus propios limites debe incorporarse a nuestra concepción de la realidad. Fsto equivale a una forma fuerte de antihumanismo; el mundo no es nuestro mundo, ni siquiera en potencia. Puede ser parcial o ampliamente incomprensible para nosotros, no sólo porque carezcamos del tiempo o de la capacidad técnica para llegar a una comprensión total de él, sino a causa de nuestra naturalcza (Ona visión de ningún lugar. Trad. J. Issa. México: Fondo de Cultura Económica, 1996 , p. 157).

- El ejemplo de un realismo respecto a lo cómico lo emplea con otro propósito Crispin Wright en Truth and Objectivity, Cambridge, Massachusetts: Harvard University Press, 1992, pp. 7-12.

'Se ha convertido en un tópico el creer que la aparicion de A Theony of Justice de John Rawls en 1971 abre una época nueva en la que la filosofía prâctica abandona los vicios metiéticos y pasa a consagrarse a las cuestiones suklantivas que en verdad merecen la pena. La apreciación es falsa porque el extraordinario valor de la obra de Rawls se debe esencialmente a que logra resultados sustantivos sólidos con una con- 
cepción nueva de la naturaleza del razonamiento práctico.

- C.S. Peirce, «Cómo esclarecer nuestras ideas», tn El hambre, un signo. El pragmatismo de Peirce, ed. J. Vericat, Barcelona: Crítica, 1988, p. 210, O, en la formulación de James: *El método pragmático [...] trata de interpretar cada noción trazando sus respectivas consecuencias prácticas. ¿Oué diferencia de orden práctico supondría para cualquiera el que fuera cierta tal noción en vez de su contraria? [...] Cuando la dis. cusión sea seria, debemos ser capaces de mostrar la diferencia prâctica que implica el que tenga razón una u otra parte." W. James, Lecciones de pragmatismo, ed. R, del Castillo, Madrid: Santillana, 1997, p. 37.

9 Putnam ha hablado de lo que sugiere Cavell en The Claim of Reason sobre el escepticismo en torno a los objetos materiales y cl tocante a las otras mentes. El primero de ellos no parece ser un problema cuya solución afecte a la vida real de la gente, mientras que el segundo sí lo hace (cstá implicado, cuando menos, el poder hacer dano impunemente a otros). Vid. H. Putnam, «Does the Disquotational Theory Solve All Problems?", en Words and Life, ed. J. Conant, Cambridge, Massachusetts: Harvard University Press, 1994, p. 277.

10 Un argumento del tipo de los que Putnam ha llamado de indispensablidad. Vid. «Philosophy of Logic», cn Mathematics, Matter, and Method, Cambridge: Cambridge University Press, 1979; y «Pragmatism and Moral Objectivityo, en Words and Life, cit. Hay traducción castellana de este Gltimo artículo en $L a$ herencia del pragmatismo, Barcclona: Paidhs, 1997.

1 Aunque no es éte el lugar de poder justificar mi tesis, sustendré que toda ética normativa minimamente rica ha de poseer tanto normas como atribuciones de bien. Quizá toda atribución de bien pueda convertirse en una norma y viceversa, pero creo que no se gana nada valioso con esta reducción. Mi argumentación posterior no dependerá de esta tesis, si bien quizá pueda contribuir a hacerla plausible en cicrto grado.

12 Ciertamente, este uso de amoralidadn está más próximo a la Sittichkeit que a la Moralität en la jerga hegeliana, lo que trae consigo complicaciones al traducir al español términos de autores alemanes más o menos deudores de la tradición hegeliana (más adelante habrá ocasión de tropezar con dichas dificultà des). Sería muy deseable llegar a un uso idiomático gue soslayara tan fastidiosos problemas, pero no acierto a imaginar cuál podría ser ese uso (no creo, por ejemplo, que seticidad pueda llegar a imponerse en el castellano ordinario ni tampoco que con ella se ganara gran cosa).
"Abreviaré por exonomía de aquí en adelante "Ética normativas como sética".

14 En alguna ocasión, Putnam ha proctamato que «la distinción entre ética normativa y metaetica tiende a derrumbarse para los pragmatistas»; vid. "La ímportancia del conocimiento no científicom, Limbo, 2 (1997), p. 11 [suplemento de Teorema, XVI/2 (1997)]. Putnam ha dado la razón a Habermas en que la conclusion weheriana de que no hay una fundamentación racional para los juicios éticos es algo serróneo desde el punto de vista intelectual y desastroso en sus cfectos sobre el "mundo de la vida" de las mujeres y los hombres corrientes" ( Pragmalism and Moral Objectivity», en Words and Life. cit., p. 151). La inquina antiweberiana de Putnant es causante de algún malentendido al respecto, según he sostenido en aCómo encajar acciones en contextos: Sobre la "comprensión explicativa" en la filosofia de la ciencia social de Max Weber*, en A. Estany, D. Quesada (eds.), Actas del II Congresa de la Sociedad de Lófica, Melodología y Filosofia de la Ciencia en España, Bellaterra: Universitat Autònoma de Barcelona, 1997, pp. 374-378.

is En otros lugares he tratado de abundar màs en este asunto. Vid. por ejemplo wiEs posible lograr un equilibrio reflexivo en torno a la noción de autonomia?", en R. R. Atamayo, J. Muguerza, A. Valdecantos \{eds.\}, El individuo y la hisforia, Barcelona: Paidos, 1995, pp. 99-131.

16 Pueden valer para el caso las observaciones de Putnam en varios lugares: «Beyond the Fact Value Dichotomy", en Reatisn with a Human Face, ed. I. Conant, Cambridge, Massachusetts: Harvard University Press, 1990, pp. 135.141; "The Place of Facts in a World of Values», op. cit., pp. 142-162; «Objectivity and the Science/Ethics Distinction, op, cit., pp. 163-178. Véase además la conferencia ya citada La importancia del conocimiento no cientificom. Han de verse también los cstudios de Ramón del Castillo, «Valores y racionalidad: Hilary Putnam y el legado de la fillosofia norteamericanam, Endoxu: Series filosóficas, 4 (1994), pp. 99-128, y «La última cara del realismo, Comentarios a una conversación con Putnam", Anabasis (Madrid), en prensa..

17 Debo esta expresión a Carlos Pcreda.

13 Sendas citas de Michael Sandal y de Alasdair Macintyre pueden scr útiles para ilustrar lo que digo: «La flosofía política [es algo] inexorable $[\ldots]$ en e] sentido de que forma parte del mundo desde un principio; nuestras prácticas e instituciones son cncarnaciones de teoría. Participar en una practica polítjca es hallarse ya en relación con la teorías [M. Sandel, "The Procedural Republic and the Unencumbered Selfs, Political Theory, 12, 1 (1984), p. 81]. aEn cada 
una [de las tradiciones], la indagación inteleciual era o es parte de la elaboración de un modo de vida social y moral del que la indagación intelcctual misma era parte integrante, y en cada una de esas tradiciones las formas de vida se hallaban encarnadas con mayores o menores grados de imperfccción en instituciones sociales o políticas cuya vida se derivaba también de otras fuentess [A. Maclntyre, Whose Justice? Which Rationality? Notre Dame (Indiana): University of Notre Dame Press, 1988, p. 349]. Estas ideas pertenecen de pleno derecho a lo que Carlos Thiebaut ha llamado «la verdad del comunitarismo» (Los fimises de la comuniala, Madrid: Centro de Estudios Constitucionales, 1992, p. 12), una verdad que, naturalmentc, no ha de obligar a prestar adhcsion a las teorias comunitaristas en hloque. Me parece que este conjunto de problemas ha de ser abordado prestando mas atención de la habitual a los fenómenos - ubicuos, según creo- de la recepción no intencionada de las teorías normativas, Me he ocupado de esto en «Entre Leviatán y Cosmópolis. Kant, Hobbes, la dicotomia hecho/valor y los efectos no intencionados de las teorías politicas", en R. R. Aramayo, J. Muguctza, C. Roldấn (eds.), la paz y el ideal cosmopolita de la Itustración, Madrid: Tecnos, 1996, pp. 275-324.

19 xThe Moral Philosopher and the Moral Lifes, en The Will to Believe and Other Essays in Popular Philasophy, Nueva York: Longmans Green \& Co, 1897, p. 184. Hay una vicja versión castellana: «Los moralistas y la vida moral", en La volunead de creer y otros ensayas de filosnfia popular, trad. S. Rubiano, Madrid: Daniel Jorro, 1922, p. 177. Sobre este articula de James es del mayor interes el estudio de Ruth Anna Putnam whe Moral Life of a Pragmatist», en O. Flanagan, A. O. Rorty (eds), Identis, Character, and Morality. Exays in Moral Psycholog, Cambridge, Massachusetts: The MIT Ptess, 1990, pp. 67-89.

21 Essays in Radical Empiricism, intr. E. K. Suckiel, Lincoln (Nebraska)/Londres: University of Nebraska Press, 1996, pp. 39-91.

21 Lo anterior se halla muy cerca de la metáfora del barco de Neurath. Vid. Foundotions of the Social Sciences, vol. II, n. 1 de Foundations of the Unity of Sciences. Toward an Luternational Encyclopaedia of Unified Science, Chicago: The University of Chicago Press, 1944, p. 47.

7 La terminologia russeltiana de kactitudes proposicionalesw, común en la filosofia analítica, puede ser sustituida sin mucha pérdida de signiticado por otras de la filosofia clasica, como los upensamientos" de Descartes ( iQué soy, entonces? Una cosa que piensa. $Y$ lqué es una cosa que piensa? Es una cosa que duda, que entiende, que afirma, que niega, que quiere, que no quiere, que imagina también y que sientex; Meditaciones metafísicas con objecionss y respuestas, Meditación segunda, trad. de $V$. Peña, Madrid: Alfaguara, 1977, p. 26) o los amovimientos del ama» de Platôn ( $\alpha \mathrm{E}$ alma $[\ldots]$ dirige cuanto hay cn cl ciclo, en la tierra y en cl mar con sus propios movimientos, a los que damos los nombres de "quertr", "observar", "prevenir", "deliberar", "opinar recta o falsamente", de "alegria", "dolor", "confianza", "miedo", "amor"»" Leyes, X, 896e-897a, trad. de I. M. Pabón y M. Fernández-Galiano, Madrid: Instituto de Estudios Políticos, 1960). El uso cartesiano es, por lo demás, extraordinariamente atin al de Frege en su trabajo "Der Gedanke $\gg$ frid. la traducción castellana de C. Pereda, "El pensamicnto. Una investigaciôn lógicam, en M. Valdés (cd.), Pensamiento y tenguaje. Problemas en la anbución de actitudes proposicionales, Mexico: Universidad Nacional Autónoma de México, 1996, pp. 23-48].

${ }^{23} \mathrm{Vtd}$. el cnsayo segundo ( $\mathrm{El}$ ciudadano y su moral: lógica de la autonomia, lógica de la autenticidads) de C. Thiebaut, El ciududano. Un sujeto reflexiwo en una sociedad compleja, Barcelona: Paidós, en prensa.

${ }^{24}$ El locus clásico es H. Frankfurt, «Freedom of the Will and the Concept of a Persons, en $G$. Watson (ed.), Free Will, Oxford: Oxford University Press, 1982, pp. 81.95. En el reciente Egomomics de Jon Flster (Barcelona: Gedisa, 1997) se encontratá abundante información solve cste problema. desde la perspectiva de la revisión elsteriana de la teoria de la elección racional. Las obras de Antoni Domènech [en particular De la ćfica a la politica (De la razón erótica a la razón inerte), Barcelona: Crítica, 1989 | son la mejor aplicación de la teoria de las preferencias de segundo orden a la filosofia práctica. Una muy inteligente critica, on ia que no podré entrar aungue sin duda mereceria la pena hacerlo, al punto de vista de Harry Frankfurt es la desarrollada pr Carlos J. Moya en sA Paradox in Compatibilist Accounts of Free Will and Moral Responsibilitym, Critica, 27 (1995), np. 119-127, y «Libertad y responsabilidad morals, en J. E. Corbi y C.J. Moya (eds,), Ensayos sobre libertad y necesidad, Valcncia: Pre-Textos, 1997, pp. 113-132.

2s Sobre lo abigarrado de la familia véase $O$. Hansbarg, La diversidad de las emociones, México: Fondo de Cultura Económica, 1996.

2. Es verdad que a veces son ambiguas, como quizá acuntezca con la nostalgia. Pero una emoción ambigua puede verse como una emóción que aún no se ha formado del todo o que está en trance de ser reelaborada por obra de alguna creencia o deseo. 
${ }^{27} \mathrm{El}$ esquema de las teorías emotjistas cra quc uno tiene una emocion y entonces profitere una pseu. doproposición, pero esto es escandalosamente unilateral. El ejemplo de la indignaciön pucde ser útil: no vale el decir que cuando me indigno digo que algo es incondicionadamente malo; más bien ocurre que, para indignarme, necesito creer que aigo es de ese típo, aunque sin duda la cmoción y la crecncia cooperan mutuamente a su formación.

3 Un caso interesante de ello es el que comenta Rafael Sanchez Ferlosio a propósito de la cláusula «ab ira tha liberanos, Domine? ("Ttes pecios", El Pais, 17 de agosto de 1997, p - 9).

$2 \mathrm{Me}$ he ocupado de esta visión del yo en «Et sujeto construido*, M. Cruz (ed.), Tiempo de subje* tividad, Barcelona: Paidos, 1996, pp. 199-220.

;) Cabria imaginar a alguien muy inmunizado contra el autodesprecio, pero, en la medida en que ese individuo interactúe mínimamente con otros, provocará seguramente emociones de desprecio en sus sentejantes. La estructura de las emociones y las creencias humanas es tal que si alguien tropieza con un individuo que contiesa alegremente kmi carácter es nauseabundo, pero ¿y qué?; es mí y no estoy dispuesto a cambiarlom, se dispara de inmediato un mecanismo que provoca el desprecio.

" He desarrollado algo más esta última idea en mi ponencia *Yoes pretéritos", presentada al Coloquio Internacional «Individus y sujeto: modelos alternativos", celebrado en la Universidad Veracruzana (Xalapa) en mayo de 1997. Las contribuciones a dicho Coloquio se publicarán próximamente en un volumen compilado por Mariflor Aguilar.

32 De esto me ncupé en mi artículo ya citado «¿Es posible lograr un equitibrio reflexivo en torno a la noción de autonomia?w, en R. R. Aramayo, J. Muguerza, A. Valdecantos (eds.), El individuo y la historia, Barcelona: Paidos, 1995, pp. 99-131. Carlos Pereda me ha propuesto hablar de xintuiciones fuertemente atrincheradas*.

3 D. Davidson, «Verdad y conocimiento: una tcoría de la coherencia”, en Mente, mundo y acción, ed. C. J. Moya, Barcolona: Pajdos, 1992, pp. 73-97.

"Fn varias exposiciones y criticas de la filosofia práctica de Habermas, "Thomas McCarthy ha hablado de "sa premisa de "una única respuesta correcta" Pueden verse el capitulo 7 de Ideals and Illusions (hay traducción castellana de A. Rivero, eEl discurso práctico: sobre la relación de la moralidad con la politicas, en Ideales e ilusiones. Reconsmuccion y deconstruccion en la teona crítica contemporánea, Madrid: Tecnos, 1992, pp. 193-212) y aLegitimacy and Diversity: Dialectical Reftections on Analytical Distinctionsw, Car- dozo Law Review, 17, 4-5 (1996), pp. 1083-1127. La respuesta de Habermas a McCarthy se encontrará en su «Reply to Symposium Participants, Benjamin N. Cardozo School of Laws, Cardozo Law Review, 17, 4-5 (1996), pp. 1477-1557. Una aportación muy sustantiva al debate se encontratá en C. Lafont, «Universalismo y pluralismo en la ética del discursor, en el presente número de Isegoriu.

3 Vid. sobre este concepto M. C. Nussbaum, *The discernment of perception: an Aristotelian account of private and public tationalitys $y$ ePlato on conmensurability and desire», en Love's Knowledge. Essays on Philosophy and Literatue, Nueva YorkOxford: Oxford University Press, 1990 , pp. 54-105 y 106-124, respectivamente.

* Las dos mejores defensas qque conozco de la existencia de conflictos morales radicales son la de $B$. Williams, «Ethical Consistency", Procedings of the Aristotelian Society, supplementary volume 39 (1965), pp. 103-124, y la de M. C. Nussbaum, eEsquilo y el conflicto práctican, en La fragilidad del bien. Fortura y ética en la tragedia y ia filosofia griega, trad. A. Balles teros, Madrid: Visor, 1995, pp. 53-87.

3 J. P. Sartre, El existencialismo es un fumanismo, trad. V. Prati, Barcelona: Edhasa, 1991, pp. 27-31.

3 Véase la formulación del dilema en los w. 205-216 del Agamenón (traducción castellana de B. Perea de las Trugedias de Esquilo con introducción de M. Fernández-Galiano, Madrid: Gredos, 1993 , p. 381). El capitulo de Martha C. Nussbaum antes citado es al mejor estudio de este dilema.

34 Es un cjemplo del noveno tropo de Sexto Empirico (Esbozos pirónicos, trad. A. Gatlego Cao y $\mathrm{T}$. Muñoz Diego, Madrid: Gredos, 1993, pp. 96-97), llamado «según los sucesos frecuentes o los raros". Sexto habla del terror que producen los cometas en comparación con el que causa el sol, pero ksi imaginamos que el sol apareciera o se pusiera muy de vez en cuando y que iluminara todo de golpe o hiciera cubrirse todas las cosas de sombras repentinamente, nos daremos cuenta del mucho terror de esa situación (p. 96). Sólo percibimos que son contlictos radicales algunos que sorprenden por lo inusual -y el problema del alumno de Sartre, como el de Agamenon, no es por ventura de los que se suscian a diario-, pero quiza lodos los casos de la experiencia moral ordinaria podrian aparecer como conflictivos si fucran infrecuentes.

40 Véanse L. Wittgenstein, Über Gewissheit, hssg. von G.E.M. Anscombe, G.H. von Wright, Oxford; Blackwell, 1979, trad. castellana de J. LI. Prades y V. Raga, Sobre la certeza, Barcelona: Gedisa, 1991, \$\$24, $115,122,220,221,247,625 ;$ y H. Putnam, Words and Lifs, cit., p. 152. 
-1 Al realista le queda franca, desde luego, la sencilla excapaturia de aducir que sólo das demásn cuestiones son las morales y que ese abigarrado conjunto de preguntas sin respuesta correcta pertenece a otro ámbito cn ol que bien no ha lugar a inquirit por la vigencia del realismo, bien puede cederse de buen grado al antirrealista. La escapatoria asi tomada es cualquicr cosa menos un dechado de elegancia, pero su dignidad intelectual pucde salir airosa si se esgrimen, como es el caso de Habermas, argumentos adicionales contra la pertinencia propiamente moral del grupo de cuestiones que se abandonan: está bien, cabe creer, que no haya una sola respuesta correcta para las preguntas sobre la felicidad y la autorrealización individual porque lo contrario acarrearia problemas muy desapacibles a la tesis, previamente adoptada como irrenunciable por razones de teoria social y de filosofia de la historia, que proclama la dicotomia estricta entre to privado y lo público. No es este el lugar de poder criticar adecuadamente la tesis de llabermas. Ha de bastarnos con proclamar que no es necesario expulsar allende los confines de la moralidad las preguntas rebeldes al realismo. Vid. J. Hahermas, aLos usos pragmáticos, éticos y morales de la razón prácticam, en M. Herrera Lima (cd.), Jirgen Habemas: moralidad, atica y politica. Propuestas y críticas, Mexico: AliantaiPatria, 1993.

42 La objeción a esto es que el autoengaño puede ser muy conveniente a veces y estar moralmente recomendado. Pcro la respuesta a esta objeción es que el autoengaño generalizado no puede justificarse y además es imposible. Vid. sobre el autoengaño D. Davidson, *Paradoxes of Irrationality", en P. K. Moser (ed.), Rationality in Aclion. Contemporary Approaches, Cambridge: Cambridge University Press, 1990, pp. 449-464.

45 La recursividad o sretlexividad de las teorías ticne una buena ilustración en el llamado "programa fuerten de la sociologia del conocimiento. Además de los requisitos de "causalidad", wimparcialidad" y wimetria», David Bloor cxigia ya en su obra de 1976 Knowledge and Social lmazery (Londres: Routledge \& Kegan Paul, pp. 4-5) la exigencia areflexiva de que los patrones de explicacion de la sociología del conocimiento tengan que aplicarse a la sociología del conocimiento misma, salvo riesgo patcnte de que el programa fuerte refute sus propias tesis. [Hay traducción castellana de los dos primeros capitulos de la obra de Bloor en L. Olivè (ed.), La explicación social del conocimiento, México: Universidad Nacional Autónoma de Mćxico, 1994, pp. 93-145]. Una muy penetrante discusión del problema de lu reflexividad sc encontrará en E. Lamo de Espinosa, La sociedad reflexiva. Sujeto y objeto dal conocimiento sociológico, Madrid: Centro de Investigaciones Sociológicas, y una demoledora crítica de las pretensiones del programa fuerte en C.U. Moulines, Pluralidad y recursiont. Estudios epistemologicos, Madrid: Alianza, 1992, pp. 110-128. Me he ocupado de los problemas suscilados por las propuestas de Moulines y de I.amo de Espinosa en wa indeterminación de los contextos. ¿Una nueva paradoja relativista?", recogido en E. de Bustos, J. Echeverria, E. Pérez Sedeño, M. I. Sánchez Balmaseda (eds.), Actos del I Congreso de la Sociedad de Lógica, Metodología y Filosofia de la Ciencia en España, Madrid: UNED, 1993, pp. 533-537, y en el ya citado «Entre Leviatán y Cosmópoliso, pp. 303-311.

4 En un reciente estudio de John Gray se contiene una aguda discusión de la tesis de Isaiah Berlin sobre la incompatibilidad o inconmensurabilidad última do los valores y concepciones del bien. John Gray se pregunta por lo que distingue al pluralismo de Berlin del escepticismo y el relativismo éticos. Scgún Gray, a Berlin debe considerársele un realista ćtico (y no, en modo alguno, un escéptico o un relativista) pucsto que su tesis de que los conflictos entre valores últimos son genuinos conflictos entre bienes irreductibles e inconmensurables corresponde a algo que subemos. Puede sostenerse la tesis de Berlin, cree Gray, en la medida en que vicne dada por unuestro conocimiento de la realidad monals (p. 85), por el hecho de que creer otra cosa sería una falsificación. Que los bienes estän en contlicto es auna caracteristica fundamental de nuestra experiencia ordinaría [...], de la misma manera que forma parte de esa experiencia que somos sujetos libres, no objetos deterministas* (ibid.). Vid. J. Gray, Isaiah Berlin, trad. G. Muñoz, Valencia: Edicions Allons el Magnànion, 1996, capitulo 2 (aPluralismom), pp. 55-101, y en particular pp. 85-86.

45 F. Schlegel, Sobre el estudio de la poesía griega, trad, B. Raposo, Madrid: Akal, 1996, p. 74. 